Pakistan Journal of Humanities and Social Sciences
Volume 8, Number 1, 2020, Pages $28-34$

\title{
A Conceptual Paper on Self-Esteem and Social Anxiety of Stutter Students' in Pakistan
}

\author{
Raja Mahtab Yasin ${ }^{1}$, Faiza Iqbal ${ }^{2}$ \\ ${ }^{1} \mathrm{PhD}$ Scholar, Capital University of Science and Technology, Islamabad, Email: mahatabmoon@gmail.com \\ 2PhD Scholar, University Utara Malaysia, Email: Faizaiqbal322@gmail.com
}

\begin{tabular}{|c|}
\hline ARTICLE INFO \\
\hline Article History: \\
\hline Received: $\quad$ February 10, 2020 \\
\hline March 01, 2020 \\
\hline March 10, 2020 \\
\hline Available Online: March 31, 2020 \\
\hline
\end{tabular}

\section{Keywords:}

Self-Esteem

Social Anxiety

Students

Pakistan

Interpersonal difficulties

Stuttering

\section{JEL Classification Codes:}

M14, M19, N15

\section{ABSTRACT}

Stuttering demands a multidimensional interpretation, as the consequences of the symptoms have been shown in recent years, with psycho-social and psychological effects shown with people living with a stutter far beyond the surface elements. This work explores the degree to which students may stutter with disabilities among school children and adults who stutter (AWS). The effect of stuttering on a person and the members of the family (siblings, parents, and partners) is discussed in this article. Such issues cover mental and social problems, self-consciousness, stuttering responses, interpersonal difficulties in everyday situations, and the overall quality of life. The effect of stuttering on the person who shares stuttering with others is illustrated. The explanation of stuttering in children and adolescents who have severe adverse effects from dealing with a stutter mentioned is explored during their existence. The impact of the stuttering condition on the parents and sisters of children who stutter is also discussed with interesting studies about the sense of connection and confidence between young people and their parents. The family obligations and expectations for parents and siblings are stressed. The focus is also on dealing with a person who stutters from their life partner's viewpoint. Presumed quality of life is discussed through unforeseen variations between the adult's quality of life and the expectations of the spouse of the individual. Eventually, there is the potential for a new appreciation and engagement strategy for people who stutter.

(C) 2020 The Authors, Published by iRASD. This is an Open Access Article under the Creative Common Attribution Non-Commercial 4.0

Corresponding Author's Email: faizaiqbal322@gmail.com

\section{Introduction}

All over the world, more than 70 million people who stutter, about $1 \%$ of the population (Bloodstein \& Bernstein-Ratner,2008). Previous studies have found that the emotional, efficacious, and social well-being of stutters (PWS) were impaired. Findings have shown that the quality of life is poorer in the fields of fitness, mental, and social welfare (Craig, Blumgart, \& Tran, 2009). In comparison to those who don't, there is a greater risk of stereotypical and psychological anxieties, community terror, and adverse effects (Tran, Blumgart, \& Craig, 2011). Nevertheless, other scholars have recently composed data disputing the degree to which PWS has certain mental health problems, particularly personality disorders (Manning \& Beck, 2013). It is also frequently cited that PWS feels ashamed and guilty and tries to hide their blows by ignoring such tones, phrases, and expression circumstances. This reluctance may become so serious that some people may not even recognize themselves as PWS to unknown or recognizable others (Murphy, Quesal, \& Gulker, 2007), and may result in severe constraints on social involvement and general well-being. Moreover, new scientific evidence has been gathered showing that PWS's romantic partners, siblings, and parents can detect the challenges they face and experience negative emotional reactions to stuttering as well. 
There has been much discussion about the significance of treating psychological, mental, and cognitive dimensions of stuttering specifically in therapy, and the efficacy of these strategies to improve outcomes for PWS. Nonetheless, other scholars suggest it is beneficial to follow a multidimensional method while clinically dealing with PWS (Guitar, 2013; Healey, Scott Trautman, \& Susca, 2004; Manning, 2004; Yaruss, 2010). The American SpeechLanguage-Hearing Association(ASHA, 2007) embraces this idea, noting that the diagnosis of communication disabilities requires treating not only the underlying disability but also the quality of life by the engagement limits, constraints in interaction, and obstacles generated by relative factors. The consequences of this are that clinicians will benefit from a broad array of resources to tackle the standard of living and well-being of stutterers in mental, emotional, and affective fields (Yaruss, Coleman \& Quesal, 2012). The scientific importance of treating stuttering in a multidimensional context has been shown. Most PWS believe that the therapy would resolve emotions and behaviors linked to stuttering (Yaruss \& Murphy, 2002) and that only speech-related concerns during and after interventions are not adequately addressed through medication (Yaruss, Quesnel, etc., 2002). Indeed, many PWS are often fearful of and worried about stuttering during fluid therapy (Cream, Onslow, Packman, et al. 2009). It was also shown that the existence of issues with mental health such as distress can hinder speakers following medication and that speech rehabilitation has not yet improved from therapy (Iverach, O'Brian, et al, 2009), and that care with cognitive elements increases the processing of world life and contributes to stressful circumstances. Treatments of cognitive elements are increasingly indicative of the bad attitudes towards the self and promoting psychosocial change (Yaruss, 2012; de Veer, Brouwers, 2009).

Recent surveys suggest that PWS may be particularly exposed to lower quality of life with increased introversion (Bleek et al., 2012). Some professionals recommend enhancing social support, activities, and participation among PWS (Craig \& Tran, 2011). The participation of support groups is a possible way of achieving this.

\section{Major problems faced by society}

Pakistan is a country where people are not aware of self-esteem and social-anxiety in stutter students. That's why they are facing problems like; bullying, teasing, teachers lack awareness \& impact their learning as well as social anxiety. They also have faced different levels of anxiety. For example, school level, adolescence level. Even their peers and their siblings bulling them. However, they are away from the awareness of self-esteem. The paper enlightens on the issues of stutter students in Pakistan and helps in giving awareness about self-esteem to overwhelm the issues of social anxiety. Stutter faces oral communication as difficult and frustrating. Societal reactions to stuttering result in social anxiety. Stereotypes are knowledge structures learned by members of a group. They can provide mental shortcuts for making sense of our environment by categorizing information about groups of people (e.g., "People who stutter are less competent"). Past stuttering disorders work has examined aspects of parental-child interaction, including parent's co-communicative behaviors, parent-language properties, attitudes, and stuttering awareness. As Yairi and Ambrose noted in 2005, investigators have largely neglected the ongoing impact of stuttering... in the family of the kid. The majority of students expressed disappointment with the way their parents tried to deal with their stuttering events.

\subsection{Bullying and teasing}

Kids that stutter face particular school difficulties. They may have social problems, with studies that reveal that over half of them are frequently mocked or tormented. Children who stutter may often be considered less normal than their fellow students. Some can slip under the radar, being quiet and silent. Stutters taunt their classmates, classes, mates only for the duration $(\mathrm{d}, 000 . . ., \mathrm{doll})$ and repeated (do, do, do, doll) prolongations. Because other people copied them while stutters talk.

\subsection{Teachers lack awareness}

Teachers may not even be conscious that they have a kid that stutters in their classroom, let alone that this kid may be nervous. Several children who stutter will fear to communicate in school or sitting at the back of the class. They may be very receptive to appraisal by teachers or peers and maybe willing, as they hate stuttering, to say "I don't know." Instead of learning to communicate with other children through movements and short phrases, they may learn to avoid difficult words or speaking opportunities. 


\subsection{Impact on learning}

It is well established that during the school years these issues have started to incubate. This means that children who stutter cannot and should not participate properly in the classroom. This is how they know and they talk badly of themselves. They worry about themselves.

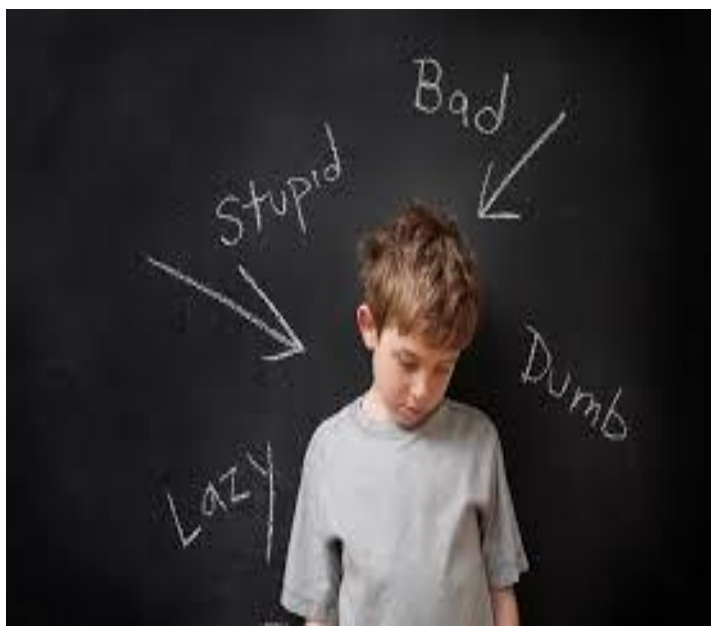

Figure 1: Impact on Learning

\section{$2.4 \quad$ Adolescence level}

The type or degree of adverse effects that stuttered expression has on disadvantaged younger age groups has not been delineated by the study. In health research, this age bracket was described as' invisible,' Those children and adolescents face major mental health risks. Issues arising in quality research on mental health include anonymity, the absence of chat with others, strong emotional feelings, and the contradictory need for time for oneself or with other adolescents, but not friends, teachers, or advisees.

\subsection{Self-esteem}

Self-esteem influences how people respond nationally against themselves. This involves general self-worth and self-consciousness (Rosenberg, 1965, 1979). It is a critical component of psychological and mental health that affects successes, accomplishments, and social activities. PWS has been shown to have self-esteem in common or equivalent limits to Whoever doesn't stutter (Tellis \& Gabel, 2003; Blu et al., 2011; Yovetich \& Flicht, 1999). These studies have, however, been conducted with teenagers and school children and not with adults. Many observational studies have shown that decreased self-esteem can result from stuttering, but due to small sample sizes, these studies are restricted in general ability.

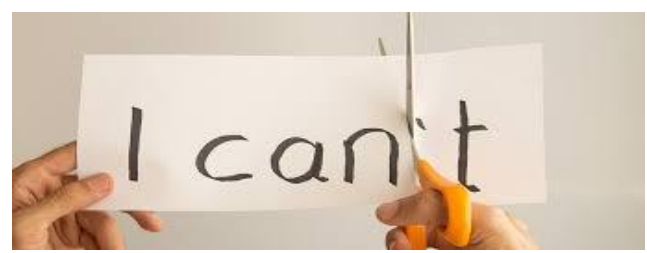

Figure 2: Self Esteem

\subsection{William James: Formula for Self-Esteem}

The author of the self-esteem movement is repeatedly referred to as William James (Hewitt, 2005; Kling et al., 1999; Leary et al., 1995; Seligman, 1996), and his "elementary human endowment" (as cited from Leary et al., 1995) can be presumed to occur since civilization was founded. It seems that the original self-esteem concept of James (1890 as cited in Seligman, 1996) is well recognized:

$$
\text { Self-esteem }=\frac{\text { Success }}{\text { Pretensions }}
$$


These aspects are inextricably linked to our feeling of positive for ourselves (pretensions) and our real performance. In thriving in the universe but by still changing the degree of our expectations or expectancies, we will feel better for ourselves. Transcript precision, utterance segmentation, coding of variations, including strain detection of volatile outputs and word function coding were achieved. Precision Four bilingual research assistants who trained in Spanish-English transcribed and coded and re-listed samples to determine if improvements in transcription and coding were required. Despite widespread field research, stuttering is a minimal concept disorder. Influenza has been linked with little predictability and apparent variations to hereditary, stress-led, and environmental factors (Craig, 2000). There are people of different origins and different manifestations of fluidity. The heterogeneous essence of stuttering makes it difficult to identify the causes of origin, chronicity, and extent. One characteristic remains curiously important: the gender disparity between men and women who tend to stutter into adulthood (Guitar 1998). A person who stutters is outnumbered women who stutter are at a scale from 2.3:1 to 5:1 (Craig, Hancock, Tran, et al., 2002) (Bloodstein, 1995). Gender distinctions have been well established for many treatments and diagnostic manuals fourth edition, text analysis (DSM-IV-TR; American Psychiatric Association 2000). These classes include greater prevalences of Attención-Deficit / Hyperactivity Disorder in males (Fayyad, de Graaf, Kessler et al., 2007), and disproportional incidence of Major Depression in women and men (Kessler, McGonagle, Zhao et al., 1994; Birmaher, Martin, Williamson et al., 1996). Many of these diseases are believed to be caused by biochemical or sociological differences.

\section{Conclusion}

We recommended and conclude that the impact of self-esteem on social anxiety in stutter students in Pakistan is very helpful and beneficial as per this William James theory. This helps the stutter students in interacting and in the social environment to enhance their selfesteem and their performance will be increased.

The consistency of the partnership between parent and child is an extremely important element in giving children social maturity models. The child's speech pathologist needs the help of the mother, the therapist, and the headteacher. Working collectively by being on the common page will mean that the child goes well with a stutter starting school. Teachers may not even realize that they have a child who is stuttering in their class, let alone nervous about this boy. Many kids often do not talk at the school or remain at the back of the classroom to prevent being noticed. This is our duty to support those who are stutters and educate their citizens around them. We will seek to increase their self-esteem so that the tests are in flying colors.

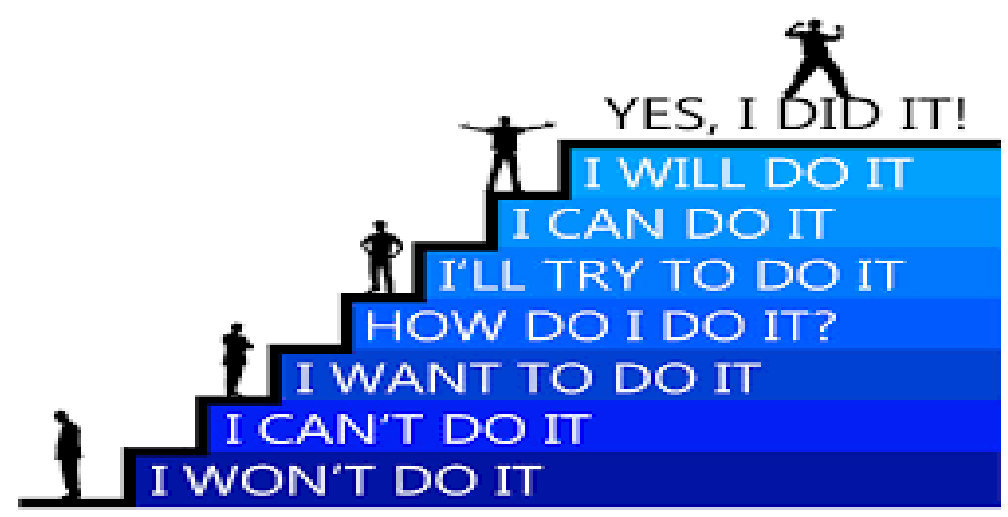

Figure 3

\section{References}

American Psychiatric Association, \& the American Psychiatric Association. (2000). Task Force on DSM-IV. Diagnostic and statistical manual of mental disorders: DSM-IVTR. Washington, DC: American Psychiatric Association, 4.

Abe, K., Abgrall, N., Ajima, Y., Aihara, H., Albert, J. B., Andreopoulos, C., \& Ariga, A. (2011). Indication of electron neutrino appearance from an accelerator-produced off-axis muon neutrino beam. Physical Review Letters, 107(4), 041801.

Bricker-Katz, G., Lincoln, M., \& McCabe, P. (2010). Older people who stutter: Barriers to communication and perceptions of treatment needs. International journal of language \& communication disorders, 45(1), 15-30. 
Boyle, M. P. (2013). Psychological characteristics and perceptions of stuttering of adults who stutter with and without support group experience. Journal of Fluency Disorders, 38(4), 368-381.

Bloodstein, O. (2006). Some empirical observations about early stuttering: A possible link to language development. Journal of Communication Disorders, 39(3), 185-191.

Birmaher, B., Ryan, N. D., Williamson, D. E., Brent, D. A., Kaufman, J., Dahl, R. E., ... \& Nelson, B. (1996). Childhood and adolescent depression: a review of the past 10 years. Part I. Journal of the American Academy of Child \& Adolescent Psychiatry, 35(11), 1427-1439.

Bothe, A. K., Davidow, J. H., Bramlett, R. E., \& Ingham, R. J. (2006). Stuttering treatment research 1970-2005: I. Systematic review incorporating trial quality assessment of behavioral, cognitive, and related approaches. American Journal of Speech-Language Pathology, 15(4), 321-341.

Beilby, J. M., Byrnes, M. L., Meagher, E. L., \& Yaruss, J. S. (2013). The impact of stuttering on adults who stutter and their partners. Journal of fluency disorders, 38(1), 14-29.

Blood, G. W., Blood, I. M., Tellis, G. M., \& Gabel, R. M. (2003). A preliminary study of selfesteem, stigma, and disclosure in adolescents who stutter. Journal of Fluency Disorders, 28(2), 143-159.

Beilby, J. M., Byrnes, M. L., \& Yaruss, J. S. (2012). Acceptance and commitment therapy for adults who stutter: Psychosocial adjustment and speech fluency. Journal of Fluency Disorders, 37(4), 289-299.

Blumgart, E., Tran, Y., \& Craig, A. (2010). Social anxiety disorder in adults who stutter. Depression and Anxiety, 27(7), 687-692.

Boyle, M. P. (2013). Psychological characteristics and perceptions of stuttering of adults who stutter with and without support group experience. Journal of Fluency Disorders, 38(4), 368-381.

Craig, A., Hancock, K., Tran, Y., Craig, M., \& Peters, K. (2002). Epidemiology of stuttering in the community across the entire life span. Journal of Speech, Language, and Hearing Research, 45(6), 1097-1105.

Cream, A., Onslow, M., Packman, A., \& Llewellyn, G. (2003). Protection from harm: the experience of adults after therapy with prolonged-speech. International Journal of Language \& Communication Disorders, 38(4), 379-395.

Cortes, J., O'Brien, S., \& Kantarjian, H. (2004). Discontinuation of imatinib therapy after achieving a molecular response. Blood, 104(7), 2204-2205.

Craig, A., Blumgart, E., \& Tran, Y. (2011). Resilience and stuttering: Factors that protect people from the adversity of chronic stuttering. Journal of speech, language, and hearing research, 54(6), 1485-1496.

Craig, A., Hancock, K., Tran, Y., \& Craig, M. (2003). Anxiety levels in people who stutter: A randomized population study. Journal of Speech, Language, and Hearing Research, 46(5), 1197-1206.

Clark, A. G., Eisen, M. B., Smith, D. R., Bergman, C. M., Oliver, B., Markow, T. A. \& Pollard, D. A. (2007). Evolution of genes and genomes on the Drosophila phylogeny. Nature, 450(7167), 203-218.

Craig, A. D., \& Craig, A. D. (2009). How do you feel--now? The anterior insula and human awareness. Nature reviews neuroscience, $10(1)$.

Cresswell, T. (2016). Black moves: Moments in the history of African-American masculine mobilities. Transfers, 6(1), 12-25.

De Veer, S., Brouwers, A., Evers, W., \& Tomic, W. (2009). A pilot study of the psychological impact of the mindfulness-based stress-reduction program on people who stutter.

Eisenberg, D. M., Davis, R. B., Ettner, S. L., Appel, S., Wilkey, S., Van Rompay, M., \& Kessler, R. C. (1998). Trends in alternative medicine use in the United States, 1990-1997: results of a follow-up national survey. Jama, 280(18), 1569-1575.

Fayyad, J., De Graaf, R., Kessler, R., Alonso, J., Angermeyer, M., Demyttenaere, K., \& Lépine, J. P. (2007). Cross-national prevalence and correlates of adult attention-deficit hyperactivity disorder. The British Journal of Psychiatry, 190(5), 402-409.

Guitar, B. (2013). Stuttering: An integrated approach to its nature and treatment. Lippincott Williams \& Wilkins.

Groenewegen, P. Joseph Shield Nicholson (1850-1927): An early student of Marshall at Cambridge, later quite critical of Marshall and his Economics. 
Guitar, B. (2003). Acoustic startle responses and temperament in individuals who stutter. Journal of Speech, Language, and Hearing Research, 46(1), 233-240.

Hewitt, K. (2005). The Karakoram anomaly? Glacier expansion and the 'elevation effect,'Karakoram Himalaya. Mountain Research and Development, 25(4), 332-340.

Healey, E. C., Trautman, L. S., \& Susca, M. (2004). Clinical applications of a multidimensional approach for the assessment and treatment of stuttering. Contemporary Issues in Communication Science and Disorders, 31, 40-48.

Hughen, K. A., Baillie, M. G., Bard, E., Beck, J. W., Bertrand, C. J., Blackwell, P. G., \& Edwards, R. L. (2004). Marine04 marine radiocarbon age calibration, 0-26 cal kyr BP. Radiocarbon, 46(3), 1059-1086.

Ingham, D., Bejan, A., Mamut, E., \& Pop, I. (Eds.). (2012). Emerging technologies and techniques in porous media (Vol. 134). Springer Science \& Business Media.

Jorenby, D. E., Hays, J. T., Rigotti, N. A., Azoulay, S., Watsky, E. J., Williams, K. E., \& Varenicline Phase 3 Study Group. (2006). Efficacy of varenicline, an a $4 \beta 2$ nicotinic acetylcholine receptor partial agonist, vs placebo or sustained-release bupropion for smoking cessation: a randomized controlled trial. Jama, 296(1), 56-63.

Johnson, D. M., Shea, M. T., Yen, S., Battle, C. L., Zlotnick, C., Sanislow, C. A., \& Gunderson, J. G. (2003). Gender differences in borderline personality disorder: Findings from the Collaborative Longitudinal Personality Disorders Study. Comprehensive psychiatry, 44(4), 284-292.

Kling, K. C., Hyde, J. S., Showers, C. J., \& Buswell, B. N. (1999). Gender differences in selfesteem: a meta-analysis. Psychological bulletin, 125(4), 470.

Kessler, R. C., McGonagle, K. A., Zhao, S., Nelson, C. B., Hughes, M., Eshleman, S., ... \& Kendler, K. S. (1994). Lifetime and 12-month prevalence of DSM-III-R psychiatric disorders in the United States: results from the National Comorbidity Survey. Archives of general psychiatry, 51(1), 8-19.

Klompas, M., \& Ross, E. (2004). Life experiences of people who stutter, and the perceived impact of stuttering on quality of life: Personal accounts of South African individuals. Journal of fluency disorders, 29(4), 275-305.

Iverach, L., O’Brian, S., Jones, M., Block, S., Lincoln, M., Harrison, E., \& Onslow, M. (2009). Prevalence of anxiety disorders among adults seeking speech therapy for stuttering. Journal of anxiety disorders, 23(7), 928-934.

Mowery, D., \& Rosenberg, N. (1979). The influence of market demand upon innovation: a critical review of some recent empirical studies. Research policy, 8(2), 102-153.

Tran, Y., Blumgart, E., \& Craig, A. (2011). Subjective distress associated with chronic stuttering. Journal of fluency disorders, 36(1), 17-26.

Reimer, P. J., Bard, E., Bayliss, A., Beck, J. W., Blackwell, P. G., Ramsey, C. B., \& Grootes, P. M. (2013). IntCal13 and Marine13 radiocarbon age calibration curves $0-50,000$ years cal BP. Radiocarbon, 55(4), 1869-1887.

Studdert, V. P., Gay, C. C., \& Blood, D. C. (2011). Saunders Comprehensive Veterinary Dictionary E-Book. Elsevier Health Sciences.

Sinclair, T. R., \& Seligman, N. A. G. (1996). Crop modeling: from infancy to maturity. Agronomy Journal, 88(5), 698-704.-

Sanderson, K. J., van Rij, A., Wade, C. R., \& Sutherland, W. H. (1995). Lipid peroxidation of circulating low density lipoproteins with age, smoking and in peripheral vascular disease. Atherosclerosis, 118(1), 45-51.

Mehta, M., Schmidt-Bleek, K., Duda, G. N., \& Mooney, D. J. (2012). Biomaterial delivery of morphogens to mimic the natural healing cascade in bone. Advanced drug delivery reviews, 64(12), 1257-1276.

Murphy, B., Quesal, R. W., \& Gulker, H. (2007). Covert stuttering. Perspectives in Fluency and Fluency Disorders, 17(2), 4-9.

Plexico, L. W., Manning, W. H., \& Levitt, H. (2009). Coping responses by adults who stutter: Part I. Protecting the self and others. Journal of fluency disorders, 34(2), 87-107.

Plexico, L. W., Manning, W. H., \& Levitt, H. (2009). Coping responses by adults who stutter: Part I. Protecting the self and others. Journal of fluency disorders, 34(2), 87-107.

Pai, M., Zwerling, A., \& Menzies, D. (2008). Systematic Review: T-Cell-based Assays for the Diagnosis of Latent Tuberculosis Infection: An UpdateT-Cell-based Assays for the Diagnosis of Latent Tuberculosis Infection. Annals of internal medicine, 149(3), 177184. 
Lau, S. R., Beilby, J. M., Byrnes, M. L., \& Hennessey, N. W. (2012). Parenting styles and attachment in school-aged children who stutter. Journal of communication disorders, 45(2), 98-110.

Lee, S. C., Shea, M., Battle, M. A., Kozitza, K., Ron, E., Turek, T., ... \& Hayes, W. C. (1994). Healing of large segmental defects in rat femurs is aided by RhBMP-2 in PLGA matrix. Journal of Biomedical Materials Research Part A, 28(10), 1149-1156.

Iverach, L., O’Brian, S., Jones, M., Block, S., Lincoln, M., Harrison, E., \& Onslow, M. (2009). Prevalence of anxiety disorders among adults seeking speech therapy for stuttering. Journal of anxiety disorders, 23(7), 928-934.

Menzies, R. G., Onslow, M., Packman, A., \& O'Brian, S. (2009). Cognitive behavior therapy for adults who stutter: A tutorial for speech-language pathologists. Journal of fluency disorders, 34(3), 187-200.

Yaruss, J. S. (2010). Assessing quality of life in stuttering treatment outcomes research. Journal of fluency disorders, 35(3), 190-202.

Yaruss, J. S., Coleman, C. E., \& Quesal, R. W. (2012). Stuttering in school-age children: A comprehensive approach to treatment. Language, Speech, and Hearing Services in Schools, 43(4), 536-548.

Yaruss, J. S., Quesal, R. W., \& Murphy, B. (2002). National Stuttering Association members' opinions about stuttering treatment. Journal of Fluency Disorders, 27(3), 227-242.

Yaruss, J. S., Quesal, R. W., Reeves, L., Molt, L. F., Kluetz, B., Caruso, A. J., \& Lewis, F. (2002). Speech treatment and support group experiences of people who participate in the National Stuttering Association. Journal of Fluency Disorders, 27(2), 115-134.

Yaruss, J. S., Quesal, R. W., Reeves, P. L., Conture, E. G., \& Curlee, R. F. (2007). Self-help and mutual aid groups as an adjunct to stuttering therapy. Stuttering and related disorders of fluency, 3, 256-276.

Wittke-Thompson, J. K., Ambrose, N., Yairi, E., Roe, C., Cook, E. H., Ober, C., \& Cox, N. J. (2007). Genetic studies of stuttering in a founder population. Journal of fluency disorders, 32(1), 33-50.

Yovetich, W. S., Leschied, A. W., \& Flicht, J. (2000). Self-esteem of school-age children who stutter. Journal of fluency disorders, 25(2), 143-153.

York, D. G., Adelman, J., Anderson Jr, J. E., Anderson, S. F., Annis, J., Bahcall, N. A., \& Boroski, W. N. (2000). The sloan digital sky survey: Technical summary. The Astronomical Journal, 120(3), 1579.

Ratner, N. B., Newman, R., \& Strekas, A. (2009). Effects of word frequency and phonological neighborhood characteristics on confrontation naming in children who stutter and normally fluent peers. Journal of Fluency Disorders, 34(4), 225-241. 